\title{
Polemik Pengarusutamaan Kesetaraan Gender di Indonesia
}

\author{
Gusti Rahma Sari' ${ }^{1}$, Ecep Ismail ${ }^{2}$ \\ 1,2 Jurusan Alquran dan Tafsir, Fakultas Ushuluddin, \\ UIN Sunan Gunung Djati Bandung \\ gustirahmasaris@gmail.com
}

\begin{abstract}
This research aims to discuss the implementation of gender equality in Indonesia. The research method is a qualitative type through literature study by applying content analysis. This research discusses the meaning, gender equality of Alquran perspective, and implementation in Indonesia. This research concludes that in the fields of education, law, family and government policies, gender equality gas been implemented. However, the issue of gender equality has not yet become mainstream so that it affecs the case of divorce in Indonesia. This research is only limited to the implementation of gender equality in Indonesia in several fields or sectors so that further research is needed in other fields. This research recommends the socialization of the concept of gender equality in the framework of Alquran to both men and women so that people get a complate understanding and create harmony.
\end{abstract}

Keywords: Alquran; Equality; Gender; Implementation.

\begin{abstract}
Abstrak
Penelitian ini bertujuan membahas implementasi kesetaraan gender di Indonesia. Metode penelitian merupakan jenis kualitatif melalui studi pustaka dengan menerapkan analisis isi. Penelitian ini membahas pengertian, kesetaraan gender perspektif Alquran, dan implementasinya di Indonesia. Penelitian ini menyimpulkan bahwa dalam bidang pendidikan, hukum, keluarga dan kebijakan pemerintah, kesetaraan gender sudah terimplementasikan. Namun, isu kesetaraan gender belum menjadi arus utama sehingga berpengaruh pada kasus cerai gugat di Indonesia. Penelitian ini hanya sebatas implementasi kesetaraan gender di Indonesia dalam beberapa bidang atau sektor sehingga perlu penelitian lebih lanjut di bidang lain. Penelitian ini merekomendasikan sosialisasi konsep kesetaraan gender dalam bingkai wahyu kepada masyarakat baik perempuan
\end{abstract}


maupun laki-laki sehingga masyarakat mendapatkan pemahaman yang utuh dan terciptanya keharmonisan.

Kata kunci: Alquran; Gender; Implementasi; Kesetaraan.

\section{Pendahuluan}

Kesetaraan gender merupakan isu yang aktual di Indonesia. Indonesia yang mayoritas penduduknya muslim, tentulah dalam menyikapi kesetaraan gender tidak lepas dari perspektif Alquran. Namun, masih banyak perdebatan mengenai kesetaraan gender di kalangan masyarakat Indonesia. Ada yang menolak karena hal ini berasal dari Barat dan merupakan gerakan semu yang tidak memberikan solusi bagi perempuan (Ulfah, 2013). Sedangkan yang mendukung karena selaras dengan konsep egalitarianisme yang diusung oleh Islam. Sehingga perlu pengkajian lebih dalam mengenai implementasi kesetaraan gender di Indonesia.

Sejumlah penelitian terdahulu telah menjelaskan berbagai hal. Antara lain Suhra, S. (2013) berjudul "Kesetaraan Gender dalam Perspektif Alqur'an dan Implikasinya Terhadap Hukum Islam" terbitan Al-Ulum-Jurnal IAIN Gorontalo. Suhra, S. (2013) menyatakan bahwa Islam mengedepankan prinsip kesetaraan antara perempuan dan laki-laki. Baik perempuan maupun laki-laki sama-sama menjadi hamba dan khalifah di muka bumi (Suhra, 2013). Rakhman, I. A. (2019) berjudul "Islam dan Egalitarianisme: Ruang Terbuka Kesetaraan Gender" terbitan at-Ta'wil: Jurnal Pengkajian AlQur'an dan At-Turats. Menurut Rakhman, I. A. (2019) bahwa Islam mengangkat egalitarianisme dan yang membedakan tingkatan manusia adalah ketakwaan kepada Allah, oleh sebab itu perempuan dan laki-laki mempunyai hak yang sama dalam mengoptimalkan potensinya (Rakhman, 2019). Khaerani, D. R. (2018) berjudul “Studi tentang Kesetaraan Gender dalam Berbagai Aspek." Khaerani, D. R. (2018) menyatakan bahwa dalam bidang pendidikan di Indonesia, telah terdapat kebijakan-kebijakan agar terciptanya kesetaraan gender dimana laki-laki dan perempuan tidak dibedakan dalam peningkatan kualitas sumber daya manusia (Khaerani, 2018). Dalam kearifan lokal Sunda, eksistensi perempuan dan laki-laki bukan untuk saling mendominasi, keduanya hidup untuk saling melengkapi (Muttaqien, 2019).

Penelitian terdahulu bermanfaat dalam menyusun kerangka berpikir penelitian ini. Kesetaraan gender adalah kondisi dimana perempuan dan laki-laki sama-sama bisa mengoptimalkan potensinya masing-masing di segala aspek kehidupan (Herien, 2013). Dalam perspektif Alquran, kesetaraan gender memiliki ruang terbuka karena selaras dengan prinsip egalitarianisme yang diusung oleh Islam (Rakhman, 2019). Implementasi 
kesetaraan gender di Indonesia sudah masuk di beberapa aspek, di antaranya agama dan pendidikan (Khaerani, 2018).

Berdasarkan paparan di atas, penulis menyusun formula penelitian, yaitu tujuan, asumsi, dan pertanyaan penelitian (Darmalaksana, 2020). Penelitian ini bertujuan untuk membahas implementasi kesetaraan gender di Indonesia. Diasumsikan terdapat implementasi kesetaraan gender di Indonesia. Pertanyaan penelitian ini adalah bagaimana implementasi kesetaraan gender di Indonesia.

\section{Metode Penelitian}

Penelitian ini merupakan jenis kualitatif melalui studi pustaka (Darmalaksana, 2020). Adapun pendekatan untuk interpretasi data digunakan analisis isi (Darmalaksana, 2020).

\section{Hasil dan Pembahasan}

Hasil penelitian dan pembahasan di bawah ini:

\section{Pengertian Kesetaraan Gender}

Isu gender berawal dari perbedaan gender dan ketidaksetaraan gender antara perempuan dan laki-laki karena konstruksi sosial, kultural dan tradisi keagamaan (Muqoyyidin, 2013). Istilah gender digunakan ahli sosial untuk menjelaskan perbedaan sifat perempuan dan laki-laki antara sifat dalam konstruksi sosial dan sifat yang melekat sebagai makhluk ciptaan (Herien, 2013). Isu gender dikembangkan di Indonesia mulai tahun 80-an dan memasuki isu keagamaan tahun 90-an (Muqoyyidin, 2013).

Asal kata gender dari bahasa Inggris yang bermakna jenis kelamin (Suhra, 2013). Gender adalah konstruksi sosial mengenai peran, fungsi, hak dan kewajiban perempuan dan laki-laki yang tidak bersifat kodrati dan dapat berubah sewaktu-waktu bahkan dapat dipertukarkan (Herien, 2013). Gender adalah pembagian peran dan kedudukan antara perempuan dan laki-laki yang dianggap pantas bagi norma dalam masyarakat (Rakhman, 2019). Menurut Lerner dalam Muqoyyidin, A. W. (2013), gender adalah tingkah laku perempuan dan laki-laki yang sesuai dengan jenis kelamin dalam masyarakat dan waktu tertentu (Muqoyyidin, 2013). Konsep gender di sini yaitu konstruksi sosial (nurture) dan bukan jenis kelamin (nature) yang melekat pada laki-laki dan perempuan dalam aspek biologis. Perbedaan gender bukanlah masalah apabila hal tersebut tidak menimbulkan ketidakadilan.

Istilah kesetaraan lebih sering dipakai dalam kajian gender, karena lebih memperlihatkan pembagian yang seimbang dan adil (Rakhman, 2019). Kesetaraan gender adalah kondisi perempuan dan laki-laki sama, sebanding dan setara dalam menikmati hak-haknya sebagai manusia di segala aspek kehidupan (Herien, 2013). Kesetaraan gender adalah konsep 
dimana perempuan dan laki-laki tidak dibatasi oleh stereotip, prasangka dan peran gender yang kaku dalam membuat pilihan-pilihan dan mengembangkan potensinya (Qomariah, 2019).

\section{Kesetaraan Gender Perspektif Alquran}

Nasaruddin Umar dalam Suhra, S. (2013) mengatakan bahwa ada beberapa variabel mengenai prinsip-prinsip kesetaraan gender dalam Alquran, yaitu sebagai berikut (Suhra, 2013).

a) Perempuan dan laki-laki berkedudukan dan mempunyai kewajiban yang sama sebagai hamba Allah (Q.S. az-Zariyat: 56). Hal ini menunjukkan bahwa dari segi taklif perempuan dan laki-laki samasama diwajibkan beribadah baik solat, zakat, puasa, haji apabila mampu dan menegakkan amar ma'ruf nahi munkar (Q.S. al-Baqarah: 183, 197, at-Taubah: 103 dan 71) (Ratnasari, 2018).

b) Perempuan dan laki-laki berkedudukan sama sebagai khalifah di muka bumi (Q.S. al-Baqarah: 30 dan Q.S. al-An'am: 165).

c) Perempuan dan laki-laki berikrar kepada Allah sebelum dilahirkan ke muka bumi (Q.S al-A'raf: 172).

d) Berkedudukan sama sebagai makhluk yang dimuliakan oleh Allah (Q.S al-Isra: 70).

e) Perempuan dan laki-laki sama-sama mempunyai potensi untuk meraih prestasi (Q.S. al-Imran: 195 dan Q.S. an-Nisa: 124).

Islam datang memberikan hak perempuan dari segi harta waris (Q.S. an-Nisa: 32) dan keilmuan (Q.S az-Zumar: 9). Walaupun bagian antara perempuan dan laki-laki berbeda, perbedaan pembagian tersebut karena tanggung jawab yang diberikan kepada kaum laki-laki lebih besar yakni menafkahi keluarganya (Ramdhan, 2016). Dari segi keilmuan, baik perempuan dan laki-laki mempunyai hak dan kewajiban mencari ilmu dan berpengetahuan. Karena Allah mengecam orang-orang yang tidak mencari ilmu (Ramdhan, 2016).

Perempuan dan laki-laki juga sama-sama memiliki balasan pahala dan dosa sesuai amal yang mereka kerjakan di dunia (Q.S. an-Nahl: 97, alMukminun: 40, al-Zalzalah: 7-8) (Ratnasari, 2018).

Alquran juga menerapkan prinsip egalitarianisme. Egalitarianisme adalah cara berpikir bahwa seseorang haruslah mendapatkan perlakuan yang sama baik dalam dimensi agama, ekonomi, sosial dan budaya (Rakhman, 2019).

Sebagaimana terdapat dalam Q.S. al-Hujurat: 13 yang menunjukkan bahwa manusia baik perempuan maupun laki-laki sama derajatnya di hadapan Allah. Yang paling mulia di sisi Allah bukanlah berdasarkan keturunan, suku, ras dan sebagainya, melainkan ketakwaannya kepada Allah (Rakhman, 2019). 
Secara historis, Islam datang membawa perubahan bagi kaum perempuan di jazirah Arab menjadi lebih baik dan mengangkat harkat martabat perempuan. Yang awalnya perempuan direndahkan kemudian menjadi sama kedudukannya dengan laki-laki. Di masa pra Islam, anak perempuan dibunuh, menikahi perempuan sesuai keinginan mereka atau tanpa batas, saling bertukar istri, dan dijadikan harta waris yang mana tidak menunjukkan adanya kesetaraan dan keadilan gender (Mazaya, 2014). Ketika Islam datang, perempuan mempunyai hak waris, dibatasi jumlah saat menikahi perempuan, bahkan banyak perempuan yang turun di sektor publik (Mazaya, 2014).

Hubungan perempuan dan laki-laki yang ditawarkan Islam ialah bersifat adil (equal) (Ramdhan, 2016). Walaupun dalam Islam ada perbedaan dalam menetapkan hak-hak, perbedaan tersebut tidak menyubordinasikan perempuan dan tetap berimbang (Ramdhan, 2016). Ayat-ayat tersebut melahirkan konsep kesetaraan yang ideal baik dalam bidang spiritual maupun non-spiritual. Perempuan dan laki-laki diberikan hak dan kewajiban yang sama. Tugas-tugas yang dibebankan kepada perempuan dan laki-laki tidak dapat terlaksana tanpa adanya kerjasama antara keduanya (Ratnasari, 2018; Noorchasanah, 2020). Dengan begitu, konsep yang ditawarkan Islam melahirkan keharmonisan antara perempuan dan laki-laki. Menempatkan segala sesuatu pada fitrah dan sesuai dengan proporsi dan potensi yang dimiliki oleh masing-masing (Ratnasari, 2018).

\section{Implementasi Kesetaraan Gender Di Indonesia}

Isu kesetaraan gender mempengaruhi kasus gugat cerai di Indonesia, salah satunya di Kabupaten Sleman (Ghozali, 2015). Dampak dari isu kesetaraan gender, kasus cerai gugat di Indonesia mengalami peningkatan karena pemahaman perempuan akan hak-haknya, kemandirian ekonomi dan pendidikan tinggi yang dimiliki istri, serta faktor utama dari kasus gugat cerai adalah ketidakharmonisan (Madrosi, 2019).

Kesetaraan gender dalam bidang hukum sudah terimplementasikan. Dalam hukum waris di Indonesia, hasil ijtihad kemanusiaan Sjadzali menyamakan antara hak perempuan dan laki-laki sedangkan Mahkamah Agung Republik Indonesia memutuskan tentang kedudukan anak perempuan dapat menghijab baik anak perempuan maupun anak laki-laki (Permana, 2018). Munculnya peraturan perundang-undangan yang memihak pada perempuan tentang syarat berpoligami dan transformasi pemikiran di bidang profesi yang mana perempuan dapat menjadi hakim (Suhra, 2013).

Di bidang pendidikan, kebijakan-kebijakan pemerintah sudah sejalan agar terciptanya kesetaraan gender dan bidang pendidikan merupakan sektor yang srategis untuk memperjuangkan kesetaraan gender (Khaerani, 
2018). Perempuan juga telah diberikan kesempatan untuk menempuh pendidikan hingga ke perguruan tinggi. Tidak seperti zaman dulu yang tamat Sekolah Dasar langsung diperintah menikah dan hanya di ruang privat. Namun, faktanya masih banyak tindakan masyarakat yang mementingkan pendidikan bagi laki-laki dibandingkan perempuan (Sumar, 2015).

Kesetaraan gender dalam keluarga juga sudah terimplementasikan. Di antaranya, pemenuhan hak yang sama dalam bidang pendidikan, pembagian tugas domestik secara merata, kebebasan dalam mengemukakan pendapat, pemilihan dan pengambilan keputusan (Qomariah, 2019).

Organisasi internasional UNDP (United Nations Development Programme) yang bermitra dengan Indonesia, telah meluncurkan programnya dalam memperjuangkan kesetaraan gender secara efektif di Indonesia (Jatmiko, 2019). Dalam menciptakan kesetaraan dan keadilan gender di Indonesia ditetapkan dalam Garis Besar Haluan Negara (GBHN) 1999, Undang-Undang Nomor 2 Tahun 2000 tentang Program Pembangunan Nasional (PROPENAS) 2000-2004, dipertegas dengan Instruksi Presiden No. 9 tahun 2000 tentang Pengarusutamaan Gender (PUG) (Rustina, 2017). Namun implementasinya masih banyak mendapat tantangan dari pola pikir dan keinginan politik terhadap pengarusutamaan gender yang masih beragam (Jatmiko, 2019). Serta belum bisa dikatakan ideal mengenai kondisi kesetaraan dan keadilan gender di Indonesia jika merujuk pada kesepakatan dalam Deklarasi Buenos Aires (Wrdhana \& Abbas, 2018).

\section{Kesimpulan}

Perbedaan gender bukanlah masalah selama terdapat keadilan di dalamnya. Kesetaraan gender adalah kondisi dimana perempuan dan lakilaki dapat berperan dalam segala bidang kehidupan tanpa dibatasi stereotip dan peran gender yang kaku. Dalam perspektif Alquran, perempuan dan laki-laki mempunyai kedudukan yang sama di mata Allah, sama-sama menjadi khalifah di bumi dan sama-sama mempunyai potensi untuk mengembangkan kapasitas yang dimilikinya. Di Indonesia, dalam bidang pendidikan, hukum, keluarga, dan kebijakan-kebijakan pemerintah sudah selaras dengan kesetaraan gender. Namun, konsep kesetaraan gender belum menjadi arus utama di masyarakat. Sehingga isu-isu kesetaraan gender berimplikasi pada peningkatan kasus cerai gugat di Indonesia. Penelitian ini diharapkan dapat bermanfaat sebagai bahan referensi dan menambah wawasan mengenai implementasi kesetaraan gender di Indonesia. Penelitian ini hanya sebatas implementasi kesetaraan gender di Indonesia dalam beberapa bidang atau sektor sehingga perlu penelitian lebih lanjut di bidang lain. Penelitian ini merekomendasikan 
sosialisasi konsep kesetaraan gender dalam bingkai wahyu kepada masyarakat baik perempuan maupun laki-laki sehingga masyarakat mendapatkan pemahaman yang utuh dan terciptanya keharmonisan.

\section{Referensi}

Darmalaksana, W. (2020). Cara Membuat Proposal Penelitian. Bandung: Fakultas Ushuluddin UIN Sunan Gunung Djati Bandung.

Darmalaksana, W. (2020). Formula Penelitian Pengalaman Kelas Menulis. Kelas Menulis UIN Sunan Gunung Djati Bandung, 1-8.

Darmalaksana, W. (2020). Metode Penelitian Kualitatif Studi Pustaka dan Studi Lapangan. Pre-print Digital Library UIN Sunan Gunung Djati Bandung.

Ghozali, M. I. (2015). Pengaruh Pemahaman Isu Kesetaraan Gender dalam Kasus Cerai Gugat di Pengadilan Agama Sleman. Yogyakarta: UIN Sunan Kalijaga. Retrieved from http:/ / digilib.uin-suka.ac.id

Herien, P. (2013). Konsep, Teori dan Analisis Gender. Bogor: PT IPB Press. Retrieved from academia.edu

Jatmiko, S. (2019). Upaya United Nation Development Programme (UNDP) dalam Meningkatkan Kesetaraan Gender di Indonesia Melalui Program Sustainable Development Goals (SDGs). Bandung: Universitas Khatolik Parahyangan. Retrieved from http://hdl.handle.net/123456789/10666

Khaerani, D. R. (2018). Studi Tentang Kesetaraan Gender dalam Berbagai Aspek. Madura: Mahasiswa Institut Agama Islam Negeri Madura. Retrieved from https:/ / www.researchgate.net

Madrosi. (2019). Kesetaraan Gender dalam Hak Cerai Menurut Hukum Keluarga Islam. Serang: UIN Sultan Maulana Hasanuddin Banten.

Mazaya, V. (2014). Kesetaraan Gender dalam Perspektif Sejarah Islam. Jurnal Sawwa, 09(2), 323-344.

Muqoyyidin, A. W. (2013). Wacana Kesetaraan Gender: Pemikiran Islam Kontemporer tentang Gerakan Feminisme Islam. Al-Ulum, 13(02), 491512.

Muttaqien, Z. (2019). Peran Perempuan dalam Tradisi Sunda Wiwitan. Khazanah Theologia, 1(1), 23-39. https:/ / doi.org/10.15575/kt.v1i1.7123

Noorchasanah, N. (2020). Hak Pendapatan Pekerja Perempuan dalam AlQur'an. Khazanah Theologia, 2(2), 111-118. https:/ / doi.org/10.15575/kt.v2i2.9207

Permana, S. (2018). Kesetaraan Gender dalam Ijtihad Hukum Waris Di Indonesia. Asy-Syari'ah, 20(2), 117-132. doi:https:/ / doi.org/10.15575/as.v20i2.3210

Qomariah, D. N. (2019). Persepsi Masyarakat Mengenai Kesetaraan Gender dalam Keluarga. Jurnal Cendikiawan Ilmuah PLS, 04(2), 52-58.

Rakhman, I. A. (2019). Islam dan Egalitarianisme: Ruang Terbuka 
Kesetaraan Gender. at-Ta'wil: Jurnal Pengkajian Al-Qur'an dan Turats, 01(01), 62-73.

Ramdhan, T. W. (2016). Tafsir Gender. Jurnal Lisan al-Hal, 08(1), 79-98.

Ratnasari, D. (2018). Gender dalam Perspektif Alqur'an. Jurnal Humanika, 18(1), 1-15.

Rustina. (2017). Implementasi Kesetaraan dan Keadilan Gender dalam Keluarga. Musawa, 09(2), 283-308.

Suhra, S. (2013). Kesetaraan Gender dalam Al-qur'an dan Implikasinya terhadap Hukum Islam. Al-Ulum, 13(2), 373-394.

Sumar, W. T. (2015). Implementasi Kesetaraan Gender dalam Bidang Pendidikan. Musawa, 07(1), 158-182.

Ulfah, I. (2013). Epistemologi Hukum Islam Muslimah Hizbut Tahrir Indonesia (MHTI) di Balik Gagasan Anti Kesetaraan Gender. Justacia Islamica: Jurnal Kajian Hukum dan Sosial, 216-244.

Wrdhana, I. K., \& Abbas, R. J. (2018). Indonesia di Persimpangan: Urgensi "Undang-Undang Kesetaraan dan Keadilan Gender" di Indonesia Pasca Deklarasi Bersama Buenos Aires pada Tahun 2017. Jurnal HAM, 09(2), 153-174. 